\title{
Design And Implementation of Online Shopping Mall System Based On ASP.NET
}

\author{
Zhang Yali, Wang Xiaokan \\ Henan Mechanical and Electrical Vocational College,Zhengzhou,451191,zhang20021026@163.com
}

Keywords:online shopping mall;B/S mode;B2C; ASP.NET

\begin{abstract}
With the globalization of Internet economy, the diversification of customer demand and the modernization of logistics technology, online shopping has become a very popular consumption pattern among many consumers, especially the younger generation. Online shopping mall system is realized by using ASP.NET technology under this situation, which not only effectively reduces the trading links, reduces the operating costs, but also improves the consumers' user experiencing. This system is an online shopping mall system designed and implemented by using B/S network structure mode, B2C business operation mode, ASP.NET and ADO.NET technology.
\end{abstract}

\section{Introduction}

The rapid development of e-commerce makes online shopping environment more mature, more and more people choose online shopping. For enterprises, online shopping makes any merchant can face consumers of the country even the world, it facilitates enterprises' development to market, reduces operating costs, enhances the core competitiveness of enterprises. For consumers, online shopping allows consumers to sit at home while can buy the needed goods easily, this model is very suitable for the people's current efficient and convenient life philosophy. Along with the development of e-commerce, the new types of payment and convenient logistics are developed, a variety of payment methods such as mobile QQ payment, WeChat payment, Apple Pay make online shopping more convenient. The effective combination of kinds of convenient conditions provides strong support for e-commerce platform to take off. This article is based on the Internet to provide a platform for people that can quickly and easily buy the healthy qualified maternal products.

\section{Analysis of demand of system}

Online shopping mall system faces are worry gens, which have to make a quick purchase over the personalized commodities with high cost performance in the interface of this system. The system shall meet the following functional requirements: beautiful and clear system interface, easy operation; all commodities can be demonstrated in categories; capable of sending notification with short messages for submitted good orders to avoid misoperation; providing new products notices for the convenience of customer learning information of new products promptly; displaying detailed properties of the commodities; providing instant messaging tools on the network and arranging support staffs for in-time response and communication to make the customer accurately and comprehensively understand the commodity and rapidly focus on the targeted customer; diversified payment method, supporting for main payment means such as UnionPay, credit card, alipay and ApplePay, etc.; setting personalized interfaces for commodity information push; easy and convenient system operation, easy maintenance; no capital information leakage of users will occur in operation of the entire system.

\section{Design of Network Architecture for Online Shopping Mall System}

The main servers 、 payment platform 、 business application server v the user terminal of online shopping mall system achieve a complete e-commerce through the Internet. The main server provides the main data service to the payment platform、 the service application server and the user terminal through the Internet; the payment gateway connects with the main server through the private line, and one payment gateway can realize the connection to the plurality of networks; the business application system is directly established on the Internet, and through the Internet, it achieves the e-commerce applications between enterprises and users 、enterprises and enterprises; Users may get a variety of ways to connect to the Internet with e-commerce integrated access platform. The network topology of the online shopping mall system is shown in Figure 1.

Business

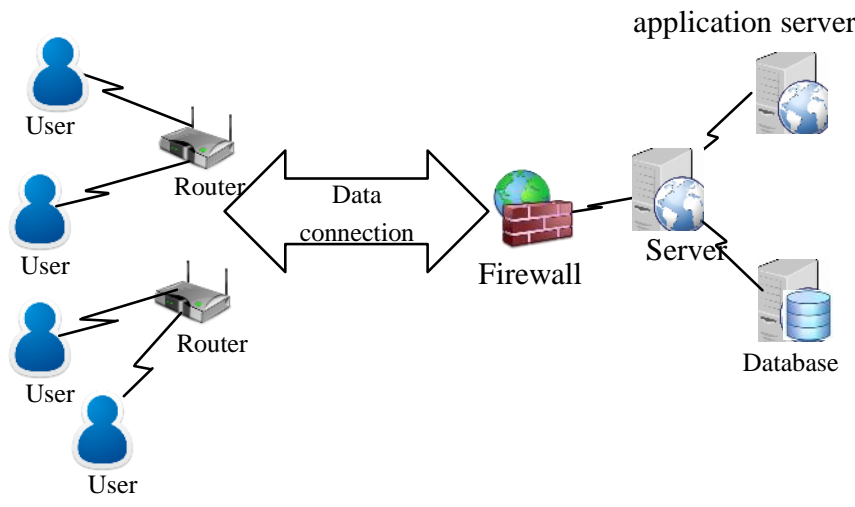

Fig .1: network topology of the online mall system 


\section{Main design philosophy}

\section{1 $\mathrm{B} / \mathrm{S}$ structure}

C / S and B / S modes are two important structural types, each one has its strong points, and Figure 1 shows the comparison between the two performances. The system needs to meet the following two points: First, reducing the requirements of client browser and operating system performance to facilitate customer operation; second, reducing the client re-overhead due to business changes and system upgrading, making the efficiency greatly improved in the process of system upgrading, using and deploying. In view of this, the system decided to select the B / S mode based on Web service.

\begin{tabular}{|c|c|c|}
\hline $\begin{array}{c}\text { structural } \\
\text { performance }\end{array}$ & C/S structure & B/S structure \\
\hline $\begin{array}{c}\text { client hardware } \\
\text { configuration }\end{array}$ & $\begin{array}{c}\text { higher hardware } \\
\text { configuration }\end{array}$ & $\begin{array}{c}\text { no special } \\
\text { requirement }\end{array}$ \\
\hline client & need to install & Need a browser \\
\hline deployment cost & relatively great & relatively small \\
\hline serviceability & complex & simple \\
\hline $\begin{array}{c}\text { network } \\
\text { compatibility }\end{array}$ & Hard & very simple \\
\hline expandability & Hard & very easy \\
\hline $\begin{array}{c}\text { corresponding } \\
\text { speed }\end{array}$ & slow & faster \\
\hline input cost & An input & multiple inputs \\
\hline
\end{tabular}

Table I: B/S、C/S structure performance comparison table

$\mathrm{B} / \mathrm{S}$ structure requires to install a browser on the client terminal, to communicate with users with vivid and diversified way, it reduces development costs and is easy to maintain. Diagram of the system technical framework is shown in Figure 2.

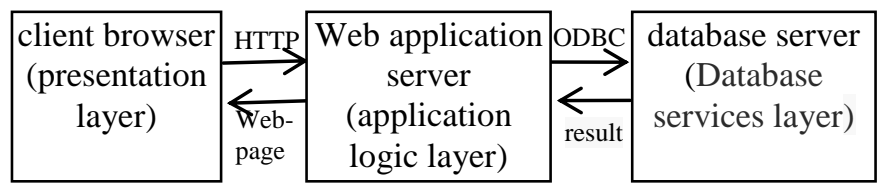

Fig. 2: Diagram of the system technical framework

The advantage of adopting this layered structure is that the problems occurring in each layer are solved at the layer, the use and data transmission of the other layers are not affected, and the post-maintenance cost can be reduced.

\subsection{B2C mode}

B2C mode, is the abbreviation of Business to Customer, it can be understood as "business-to-customer" in the era of e-commerce, is a mode of e-commerce, which is the usually said retail business mode that directly selling products and services to consumers. The logic of the formation of B2C mode is that the entrepreneur integrates the effective resources and then transmits to the market with needs. As this system needs to reflect the personalized custom and directly faces to the users, so the use of B2C mode is most appropriate.

\section{The Realization of Key System Technology}

The realization of key system is system security technology data consistency technology, paging display technology.

\subsection{System Security Technology}

Online shopping system is a trading platform between users and enterprises, so data security is very important. In order to ensure the security of the system, the system takes two steps to ensure the security: (1) user authentication basing on HTTPS. Surfing on the Internet are generally by the HTTP protocol, the default data is transmitted in plaintext, the data in the transmission process may be captured and eavesdropped, so it is not safe, but the use of HTTPS user authentication can guarantee that the user information is not leaked. (2) Database encryption / decryption technology; Previous versions of SQL Server did not support encryption, and SQL Server 2005 first adopts column-level encryption. SQL Server 2008 adopts transparent data encryption (hereinafter referred to as TDE), TDE encryption is a kind of database. According to the database program or the user, this kind of encryption was no encryption. The encryption and decryption of data is performed on a page basis and performed by the data engine. Encrypted at the time of writing while decrypted when read out.Four steps of using TDE:

(1)Create a master key

USE master;
CREATE MASTER KEY ENCRYPTION BY
PASSWORD = 'P@sswOrd';
(2)Create or obtain a certificate protected by the master key
CREATE CERTIFICATE MyServerCert WITH
SUBJECT = 'My DEK Certificate';

(3)Create a database encryption key and protect it by the certificate

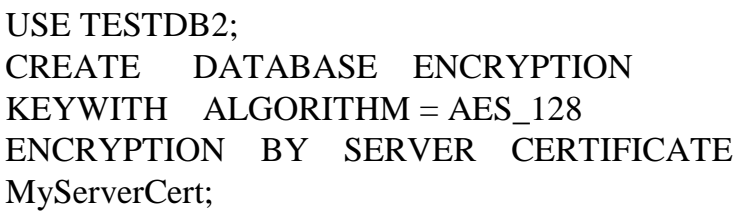




\subsection{Data Consistency Technology}

Online shopping system is running on an open network, as a result, it requires a more secure, stable and reliable system. This requires the design and implementation of the system should take into account the occurrence of a variety of accidents, such as property losses of users and corporate caused by information loss. In order to avoid the occurrence of such events, you can use the database transaction mechanism to ensure the consistency of interactive data. In the field of E-commerce, the absolutely strong consistency is too idealistic, but you can choose the final real-time consistency. In the transaction creation process, you first create an invisible order, and when synchronously calling the lock coupons and deducting the inventory, you can issue a pending message to the MQ for the calling exception (failure or timeout). If the message fails to send, the local will do a step-by-step asynchronous retry; after receiving a message, coupon system and inventory system will judge whether to do business rollback, so that it can ensure the final consistency of many local affairs in quasi real-time.

\subsection{Paging Display Technology}

The system database stores huge product information, if all of this information is displayed to one page, not only a waste of time to load, but also the interface is not good, so you must take paging display to display all the goods by page after the information classification. The data of paging display are all from the database, the system achieves paging through the stored procedure, and each pagination is realized by reading part of the data in the database. Before reading the database, the stored procedure has calculated the speech data interval, and then just by reading the data from the interval to implement the paging. Part of the tab code is as follows:

protected void PageLoad(object sender, EventArgs)

$\{$ if (!IsPostBack)

\{ int PageCount,PageIndex,PageSize;

SCN.Open();

SCM.CommandText = "select $\operatorname{count}(*)$ from tdbLevMe ss ";

SCM.Connection $=\mathrm{SCN}$;

int ReCount $=$ Convert. ToInt32(SCM.ExecuteScalar().

ToString());

SCN.Close();

Session.Add("PageSize", 20);

PageSize = Convert.ToInt16(Session["PageSize"]);

PageCount $=$ ReCount $\%$ PageSize $==0$ ? ReCount $/$ Pag

eSize: ReCount / PageSize + 1;

Session.Add("PageCount", PageCount);

PageIndex = 1;

Session.Add("PageIndex", PageIndex);

GridView_Init (PageSize, PageIndex);

LinkBut1.Enabled = false; LinkBut2.Enabled = false;

LinkBut3.Enabled = true; LinkBut4.Enabled = true;

Label1.Text $=$ "第 "+PageIndex.ToString ()$+$ " 页 $/$ 共 " + PageCount.ToString ()$+$ "页"; \}

i)

\section{Conclusions}

This system is an online shopping mall system designed and implemented by using B/S network structure mode, B2C business operation mode, ASP.NET and ADO.NET technology.If getting the support of mobile phone App, the system would be icing on the cake.

\section{Acknowledgments}

This work was supported by the youth backbone teachers training program of Henan colleges and universities under Grant No. 2016ggjs-287, and the project of science and technology of Henan province under Grant No. 172102210124.

\section{References}

[1] Sudhakar Krishnan, Rubini Pandu, Mangai A Fuzzy Based Link Analysis for Mining Relational Databases[J]. Control Theory and Informatics, 2015

[2] Suhasini Itkar, Uday Kulkarni. Efficient Frequent Pattern Mining Using Auto-Associative Memory Neural Network[J]. British Journal of Applied Science \& Technology, 2014, 4(22)

[3] Gajendra Sharma, Wang Lijuan. Ethical perspectives on e-commerce: an empirical investigation[J]. Internet Research, 2014, 24(4)

[4] JrJung Lyu, Ru-Ching Hsu, Chang-Yu Chen. An The empirical study of application service provider (ASP) adoption in SMEs[J]. International Journal of Electronic Business Management, 2009, 7(1)

[5] Shi Huiying, She Guanghui. Design of Call Center Knowledge Base System Based on ASP and SQL [J]. Electronic Technology and Software Engineering. 2015.(6)

[6] Qiu Huicui. Design and Implementation of Maternal and Infant Online Shop System Based on ASP.net [D]. Master Thesis of South China University of Technology. 2012

[7]Yan H. Design and Implementation of Shopping Mall System based on Image[J]. Journal of the Royal Asiatic Society of Great Britain \& Ireland, 2012, 17(11):120-122.

[8]Yeo J M, Shin U J, Zheng B W. The Data Model based Design and Implementation of a Shopping Mall System[J]. Kips Transactions Parta, 2009, 16A(4):273-288.

[9]Wen C H, Zhang W. The Design and Implementation of Online Shopping Mall Based on JSP[J]. Computer Knowledge \& Technology, 2010.

[10]Ye G Z, Liu X W, Jiang W X. Design and Implementation of Online Shopping System Based on MVC Frameworks[J]. Applied Mechanics \& Materials, 2014, 687-691:2466-2469.

[11]Gao L, Liu Q, Jiang X. The Design and Implementation of the Online Shopping System for 
Digital Arts[C]// Ninth International Symposium on Distributed Computing and Applications To Business Engineering and Science. IEEE Xplore, 2010:414-416.

[11]Yao Y. Design and implementation of online mall shopping system based on $\mathrm{Web}[\mathrm{J}]$. Modern Electronics Technique, 2016.

[12]Hong W, Weng Y, Xie L, et al. Design and implementation of web-based DSS for online shopping mall[C].IEEE International Conference on Control and Automation. IEEE, 2009:1308-1313.

[13]Gao L, Liu Q, Jiang X. The Design and Implementation of the Online Shopping System for Digital Arts[C]// Ninth International Symposium on Distributed Computing and Applications To Business Engineering and Science. IEEE Xplore, 2010:414-416.

[14]Hong W, Weng Y, Xie L, et al. Design and implementation of web-based DSS for online shopping mall[C]// IEEE International Conference on Control and Automation. IEEE, 2009:1308-1313.

[15]Hui M A, Ya-Qi M A. Based on JSP online acquisition system design and implementation[J]. Journal of Ningbo Polytechnic, 2011.

[16]Liu Y L, Liang Y, Cheng Y Y. Design and implementation of image acquisition system based on ARM and Linux[C]// International Conference on Electronics and Optoelectronics. IEEE, 2011:V3-49-V3-52.

[17]Zuo L X, Deng F F, Shan L U. Design and implementation of a high-speed data acquisition system based on DSP[J]. Power System Protection \& Control, 2010. 